of the community ecology of megaherbivores, and which result from the cessation of exploitation and sudden population increases in habitats whose structure changed while numbers were kept low.

The middle chapters of the book vary in scope. In some, for example those on nutrition, feeding ecology, reproduction and ecosystem processes, Owen-Smith can consider all megaherbivores as a group, and tests well-defined hypotheses. In others, such as those on behaviour and demography, differences between the species force less interesting species-byspecies summaries of data. All chapters provide good literature reviews.

Most of the book is a prelude to two arguments presented at the end, where Owen-Smith puts forward explanations of the Pleistocene extinctions and discusses the conservation of surviving species. Megaherbivores, once distributed over all continents, are now restricted to eight species in Africa and tropical Asia. Only hippos and giraffes appear to be safe over most of their range. Yet local problems of overpopulation show that "megaherbivores are embarrassingly successful when protected from human depredation".

The explanation for Pleistocene extinctions has human overexploitation as the main driving force, but takes into account climatic shifts and changes in habitat characteristics. Owen-Smith suggests that it was hunting that caused the demise of megaherbivores, especially in North America and Europe, and that changes in habitat (leading to extinction of some smaller species) were an effect and not a cause of their disappearance.

The chapter on conservation is excellent. Owen-Smith believes management is necessary for conservation, because artificial habitat fragmentation prevents dispersal of animals. He also recognizes that 'overgrazing' and 'overpopulation' are not biological realities, but reflect management choices. Protected from poaching, megaherbivores could recover to levels where light exploitation would be both feasible and desirable - but "without effective controls of illicit markets, populations of these great beasts will be driven inexorably towards extinction".

Marco Festa-Bianchet is NATO Science Fellow in the Large Animal Research Group, Department of Zoology. University of Cambridge, Downing Street, Cambridge CB2 3EJ, UK.

\section{New in Britain}

- What Mad Pursuit: A Personal View of Scientific Discovery by Francis Crick. Publisher is Weidenfeld \& Nicolson, price is $£ 12.95$. For review see Nature 336, 268 (1988).

\section{New in paperback}

- Bones of Contention by Roger Lewin. Publisher is Penguin, price is $£ 5.99$. For review see Nature 330, 277 (1987).

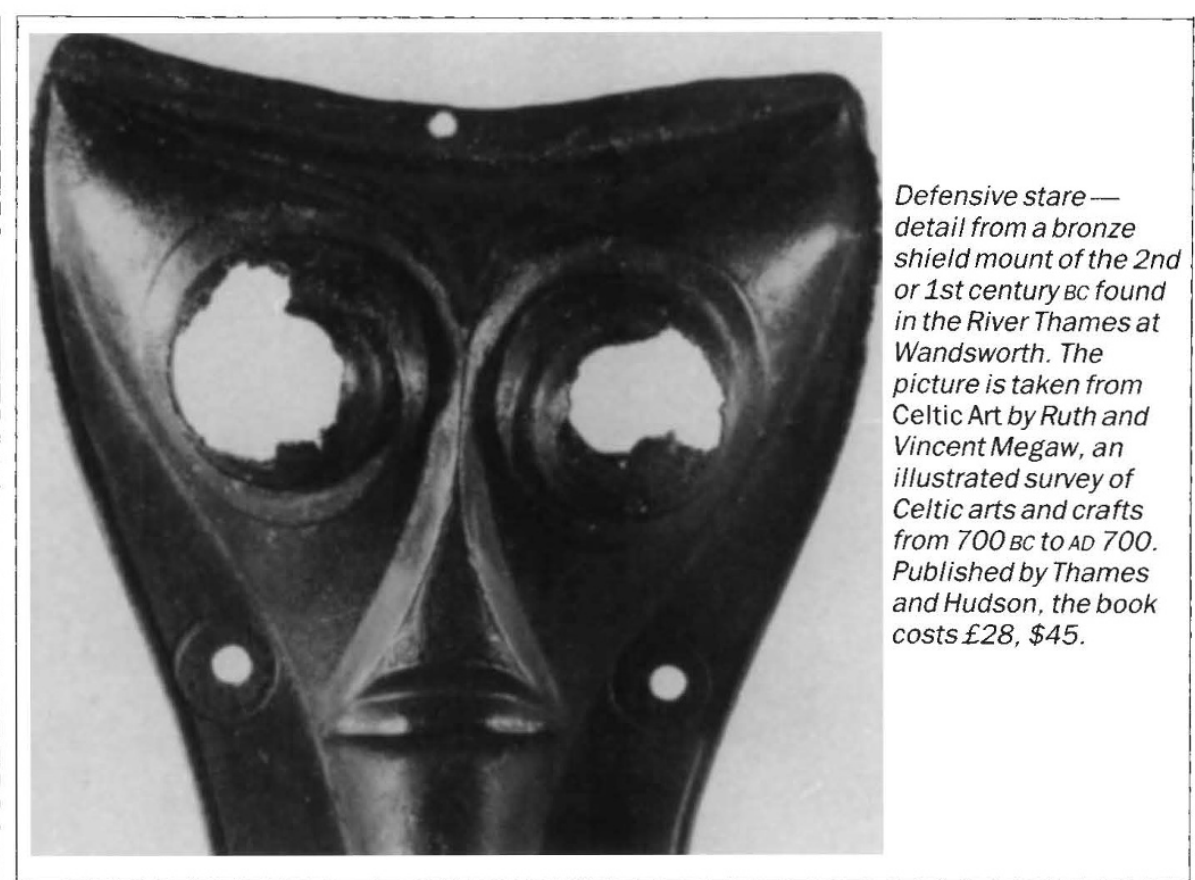

\section{On course for a better life?}

\author{
F.E.G. Cox
}

The Biology of Parasitism. Edited by Paul T. Englund and Alan Sher. Alan R. Liss: 1989. Pp. 544. Hbk \$90, pbk $\$ 45$. Distributed in Britain by Wiley, hbk £68.85, pbk £35.50.

EACH summer since 1980, a small group of young scientists has gathered at Woods Hole to attend a course on advances in the molecular biology and immunology of parasites. The course is given by acknowledged experts from all over the world, and serves as a barometer of the state of the subject. In this volume, a number of the lecturers have attempted to convey its flavour and spirit to a wider audience. In all, 41 scientists have contributed 28 chapters, grouped into biological, immunological and molecular biological, biochemical and genetic aspects of parasitism, to produce a book that attempts to reflect the present state of our knowledge and to be an essential aid in undergraduate and postgraduate teaching.

The stated aim is to emphasize concepts rather than review research data, but sadly some of the authors have ignored this principle and the volume is thus very varied in content. Things get off to an excellent start with accounts of the global impact of parasitic diseases by Ken Warren, and of parasitic zoonoses by George Nelson, which set the scene. There are also specialized chapters on human schistosomiasis, amoebiasis, American leishmaniasis and trypanosomiasis and, towards the end, on toxoplasmosis, that are stimulating and make provocative points.

The first SDS-PAGE gel appears on page 97 , closely followed by the inevitable contributions on the surface antigens of Plasmodium falciparum, thick with facts and thin on concepts. The surface antigens of trypanosomes also receive considerable attention in three chapters; in one of them, John Donelson manages to concentrate on essentials and to ask interesting questions, as does Alan Sher in his contribution on vaccination. Fresh ground is explored by C.C. Wang, who considers new targets for chemotherapy, but his is the only contribution on this important area. Most of the remaining chapters are largely mini-reviews of topics covered in depth elsewhere.

Overall, this collection of articles represents a fair overview of present-day parasitological research and pin-points the unevenness of the subject's coverage. The important matter is the extent to which knowledge gleaned in the main laboratories of the world can be applied to the immense problems outlined by Ken Warren, and it is disturbing that most of the questions asked are of an academic rather than a practical sort. Equally disturbing is that scrutiny of the faces in the photographs of those who attended the last eight courses reveals that only three are black. One is tempted to ask whether parasites are important because they are the playthings of immunologists and molecular biologists or because they are daily life-threatening components of the environment for millions of people. Whatever the answer, the editors have produced a book that is useful, readable and well worth having.

F.E.G. Cox is a Professor in the Division of Biomolecular Sciences, King's College London, 26 Drury Lane, London WC2B 5RL, UK. 